\title{
Contents
}

\section{Studying Low-Dimensional Structures by Phonon Imaging}

by A.J. Kent

119

Job Positions by Internet

121

NOBEL MEETING, LINDAU

Laureates Come Down to Earth...

122

The Physics of Electronic and Atomic Collisions

132

EPAC'94: Accelerators Remain a Driving Force

133

EAS: Creating Regional Coherence

136

OECD: Spending and Sources

137

FSU JOURNALS: First Journals Delivered

EPS DIRECTORY

Executive Committee; Council; Action Committees 123

National Societies

124

Associate Members

125

EPS Divisions

EPS Interdivisional Groups

126

Collaborating Societies

Meetings; Journals

International Organizations

EU Programmes; World-Wide Web

128

128

129

129

131

- Europhysics Notes

Academies' rôle; ESRF oversubscribed;

ITER-EDA; WWW Organization: ICSTI survey

European Physical Society

Europhysics News is the journal of the European Physical Society that acts through Divisions, Sections and Groups to promote collaboration among physicists. Subscription price: SFR 135-- per annum.

\section{Editorial Board}

P. Bochsler, Bern University

S. Ciliberto, ENS, Lyon

A.-J. Dianoux, ILL, Grenoble

Editor: P.G. Boswell

Exec. Sec.: G. Thomas

T. Jarlborg, Geneva University

J. Schacher, Bern University

M. Siegrist, EPFL, Lausanne

President: N. Kroó KFKI, Budapest

Editorial and Advertising

EPS Secretariat, P.O.Box 69

$\mathrm{CH}-1213$ Petit-Lancy 2, Geneva

Telephone: +41 (22) 7931130

Telefax: $\quad$ +41 (22) 7931317

E-mail: epnews@cernvm.cern.ch

Advertising is charged according to space, on a sliding scale ranging from SFR 2700.- for a full page to SFR 700.- for a one-sixth page. Rates for four-colour and cover advertising, and series insertions, on application. Special rates for Associate Members of EPS; $25 \%$ reduction for announcements of situations vacant.
Deadline for advertising orders:

first week of month of publication.

\section{Subscriptions \& EPS Fees:}

Société de Banque Suisse,

Geneva; Acc. No. 164.899

Swiss Post Office Acc.: CCP

Geneva 12-19107-4

German Post Office Acc.: Postbank

Karlsruhe 1801-30-754

Eurocheque to EPS, Geneva

EPS Budapest Secretariat

Nádor u. 7, H-1051 Budapest

Telephone: $\quad+36(1) 1173510$ Telefax: $\quad+36(1) 1176817$

\section{Cover illustration}

EPAC'94 highlights (see page 133). Right, upper: three-dimensional beam diagnostics. A streak camera image of $C^{6+}$ bunches at 250 $\mathrm{MeV} / \mathrm{u}$ in equilibrium with the electron cooling for a beam in the reinjection line between the ESR and SIS rings at GSI, Darmstadt. The colour-coded image gives the horizontal density profile as a function of time (vertical direction). On using it to determine the horizontal emittance along the bunch as a function of time it was found that the emittance remained constant, in disagreement with theory and suggesting that a modified temperature distribution is needed. Courtesy: I. Hofmann, GSI, Darmstadt.

Left, lower: a numerical simulation of a $120 \mathrm{GHz}$ planar RF-structure suited for micromechanic fabrication. The drawing shows the accelerating field lines and the bottom half of a structure with a linear array of cavities (the beam would pass between this half and the half that is not shown). Courtesy: H. Henke, TU Berlin.

Employment statistics are notoriously difficult to obtain, especially in a recession when there is a tendency not to say too much. The Organization for Economic Co-operation and Development (OECD) in its latest statistics (see page 137) notes that the number of researchers in OECD countries grew by $4.8 \%$ p.a. in the period $1981-85$ and by $3.9 \%$ p.a. in the period $1985-89$. The growth rate fell sharply in industry (6.3\% p.a. for $1981-85$ to $3.9 \%$ p.a. for $1985-89$ ), although the then European Community countries managed to maintain a growth rate of $4.2 \%$ p.a. throughout 1981-89 for industrial researchers.

This encouraging tendency for European industry to take on researchers during the 1980 s is reflected by scattered employment statistics for physicists in several countries. In The Netherlands, for example, the percentage of graduating physicists who went on to work in industry increased from $42 \%$ in $1970-79$ (about 1300) to $49 \%$ in $1980-89$ (about 2000). As overall R\&D spending has been decreasing recently (see page 137), and since some $70 \%$ covers staff costs, it is hardly surprising that the current situation appears not to be so optimistic. For instance, the percentage of graduates in The Netherlands who went to work for industry dropped to $20.4 \%$ in $1990-93$.

It seems that graduates are being increasingly absorbed into the universities in temporary posts. The effect is difficult to quantify because the Dutch statistics, for instance, suffer from a relatively low response rate

(55\% instead of the usual $70-85 \%)$. Moreover, temporary staff in academia tend to respond better than other categories to questionnaires, so any data probably overestimate the number of graduates moving into universities. To further cloud the picture, the increased academic uptake may be a real effect. For example, a recent follow-on to a 1992 survey of physics in Denmark shows that universities are starting to anticipate an accelerating rate of retirements as a direct consequence of a major expansion in the $1960 \mathrm{~s}$. In any event, more accurate and extensive statistics are needed, and moves are under way in EPS to carry out a survey of employment in Europe (the last was in 1986).

Helping graduates find positions has become a major preoccupation of many organizations, and several have turned to new technology in the form of computer servers over Internet. A list of what seems to relevant for physicists is published on page 121. The number and types of services have evolved very rapidly this last year or two, and readers will note the replacement of old systems based on subscribing to a list by sending an email message. The current approach is to interrogate a list with links to references using a browser over World-Wide Web (WWW). This truly impressive approach is probably here to stay, hopefully under adequate steering by the new WWW Organization that aims to ensure a stable development (see page 140).

The WWW approach will often be complemented by simple telnet commands and by other ways to download a file (e.g., by anonymous FTP) if one does not have access to the Web. Nonetheless, the need to join the Web must surely be reaching critical proportions if young people are to profit from the new employment servers. Fortunately, the point has at last arrived when you do not need to have a workstation hard-wired to Internet. All that is required is a desktop computer and an up-to-date modem working over a standard telephone line connected a local call away to a helpful institute or to a commercial or semi-commercial service via a serial connection. You can then download from servers free software to run the serial link and free WWW browsers for PCs, Macs, Unix boxes, etc. to scan the "pages" of the multitude of Web servers (for the downloads, it helps to have a program that runs anonymous FTP). EPS has launched a WWW server (page 131) and is looking at ways to run a full service in coordination with national physical societies.

P.G. Boswell 